\title{
SNPs within the GH-signaling pathway are associated with the early IGF1 response to GH replacement therapy in GHD adults
}

\author{
Camilla A M Glad', Edna J L Barbosa ${ }^{1,2}$, Helena Filipsson Nyström', \\ Lena M S Carlsson ${ }^{3}$, Staffan Nilsson ${ }^{4}$, Anna G Nilsson ${ }^{1}$, Per-Arne Svensson ${ }^{3}$ \\ and Gudmundur Johannsson ${ }^{1}$ \\ ${ }^{1}$ Department of Endocrinology, The Sahlgrenska Academy, University of Gothenburg, Gröna Stråket 8, \\ Vita Stråket 15, SE-413 45 Göteborg, Sweden, ²Serviço de Endocrinologia e Metabologia do Hospital de \\ Clínicas da Universidade Federal do Paraná, 80030-100 Curitiba, Brazil, ${ }^{3}$ Department of Molecular and Clinical \\ Medicine, The Sahlgrenska Academy, University of Gothenburg, SE-413 45 Göteborg, Sweden and ${ }^{4}$ Department of \\ Mathematical Statistics, Chalmers University of Technology, SE-412 96 Göteborg, Sweden
}

Correspondence should be addressed to C A M Glad

Email

camilla.glad@medic.gu.se

\begin{abstract}
Objective: GH-deficient (GHD) adults have reduced serum concentrations of IGF1. GH replacement therapy increases serum IGF1 concentrations, but the interindividual variation in treatment response is large and likely influenced by genetic factors. This study was designed to test the hypothesis that single-nucleotide polymorphisms (SNPs) in genes within the GH signaling pathway influence the serum IGF1 response to $\mathrm{GH}$ replacement.

Design and methods: A total of 313 consecutive GHD adults ( $58.1 \%$ men; mean age 49.7 years) were studied before and after 1 week, 6 months, and 1 year of GH treatment. GH dose was individually titrated to normalize serum IGF1 levels. Six SNPs in the GH receptor (GHR) and the GH signaling pathway (JAK2, STAT5B, SOCS2, and PIK3CB) genes were selected for genotyping. The GHR exon 3-deleted/full-length (d3/fl) polymorphism was analyzed using tagSNP rs6873545.

Results: After 1 week of GH replacement, homozygotes of the fl-GHR showed a better IGF1 response to GH than carriers of the d3-GHR $(P=0.016)$. Conversely, homozygotes of the minor allele of $P I K 3 C B$ SNP rs361072 responded better than carriers of the major allele $(P=0.025)$. Compared with baseline, both SNPs were associated with the IGF1 response at 6 months $(P=0.041$ and $P=0.047$ respectively), and SNP rs6873545 was further associated with the IGF1 response at 1 year $(P=0.041)$.

Conclusions: Our results indicate that common genetic variants in the $\mathrm{GH}$ signaling pathway may be of functional relevance to the response to $\mathrm{GH}$ replacement in GHD adults.
\end{abstract}

\section{Introduction}

In adults, hypopituitarism and untreated growth hormone deficiency (GHD) are associated with a metabolic syndrome-like phenotype (1) and an almost doubled risk for vascular mortality (2). GH replacement therapy improves the metabolic abnormalities, but there is considerable variability in treatment response. Clinical variables, such as sex, age, BMI, GH dose, and the route of estrogen replacement in women have been linked to the response to $\mathrm{GH}$ replacement $(3,4,5)$, but together these factors only explain a small part of the variability in GH treatment effect (6). Genetic factors, such as polymorphisms in genes within the $\mathrm{GH}$ signaling cascade, may also influence the responsiveness to $\mathrm{GH}$. In this context, the $\mathrm{GH}$ receptor (GHR) exon 3-deleted/full-length $(\mathrm{d} 3 / \mathrm{fl})$ polymorphism is the most intensively studied variant.
(C) 2014 European Society of Endocrinology Printed in Great Britain
Published by Bioscientifica Ltd. 
The d3-GHR has been suggested to confer a more GH-sensitive receptor, and in GHD short children carriers of the d3-allele have in many studies, although not all, been shown to respond better to GH in terms of growth velocity and final height than noncarriers (7). Studies on adult GHD populations have produced more conflicting data, showing either no association or a better response in carriers of the d3-GHR $(8,9,10,11)$. Previous studies have, however, focused on the long-term (>6 months) response to GH replacement therapy, rather than the early response.

At the molecular level, responses to $\mathrm{GH}$ are mediated by the GHR encoded by the GHR gene, located on chromosome 5, region p13.1-p12 $(12,13)$. Binding of GH to the GHR leads to rotation within the GHR subdomains and results in transphosphorylation and activation of the GH signaling cascade, which involves the JAK2/STAT5 pathway $(14,15)$. Eventually, this activation leads to an increased generation of insulin-like growth factor 1 (IGF1). GH also activates the suppressor of cytokine signaling (SOCS) genes, which mediates an inhibitory effect on the GH signaling $(16,17)$, thereby producing an intracellular negative feed-back loop. In addition, some of the metabolic effects of GH are the results of activation of phosphoinositide 3-kinases (PI3Ks) (18), such as phosphatidylinositol-4,5-bisphosphate 3-kinase, catalytic subunit beta (PIK3CB), effects which are thought to be independent of the GHR-induced IGF1 generation.

Several polymorphisms in genes within or directly downstream of the GH signaling pathway have been identified, and previously suggested to be of functional importance. The PIK3CB single-nucleotide polymorphism (SNP) rs361072 has been associated with insulin sensitivity (19), serum IGF1 levels, and longevity (20). Two SNPs in the JAK2 gene have been associated with central adiposity (rs7849191) and blood lipid levels (rs3780378) (21). Lastly, STAT5B SNP rs6503691 has been associated with breast cancer (22) and cholesterol levels in children with idiopathic GHD before, during, and after GH replacement (23), and SOCS2 SNP rs11107116 has been associated with peak height velocity during puberty (24) and adult height (25).

The overall aim of this study was to test the hypothesis that SNPs in genes within the GH signaling cascade are associated with the serum IGF1 response during GH replacement therapy. The specific aim was to investigate this association during short- and long-term GH replacement therapy.

\section{Subjects and methods}

\section{Patients}

The patients enrolled in this study are part of a larger longitudinal clinical trial, carried out on adults with hypopituitarism and GHD $(n=457)$ treated at the Sahlgrenska University Hospital (Gothenburg, Sweden). In this project, patients who refused genetic testing $(n=51)$, with missing data during their 12 months of GH replacement therapy $(n=51)$, who were enrolled in another study $(n=28)$, or had compliance problems $(n=14)$, were excluded, resulting in a cohort of 313 GHD adults (58.1\% men) with an average age of 49.7 years (range 17-77). The clinical characteristics of the patients are shown in Table 1. Patients had a well-defined hypothalamic-pituitary disease and the diagnosis of GHD was confirmed as described elsewhere (26). Two hundred and eighty-one patients had adult onset GHD (AO-GHD) and 32 cases were childhood onset (CO-GHD). None of the AO-GHD patients had previously received GH treatment. CO-GHD patients had previously received GH therapy, but it had been discontinued at least 4 years before they

Table 1 Baseline characteristics of 313 adult patients with GHD. Data presented as mean or percent.

\begin{tabular}{ll}
\hline Etiology & $\boldsymbol{n}(\%)$ \\
\hline NFPA $^{\mathrm{a}}$ & $128(40.9)$ \\
Idiopathic GHD & $29(9.3)$ \\
Prolactinoma & $27(8.6)$ \\
Craniopharyngeoma & $24(7.7)$ \\
Hypophysitis & $22(7.0)$ \\
Previous Cushing & $20(6.4)$ \\
Previous acromegaly & $10(3.2)$ \\
Other etiologies & $53(16.9)$ \\
Pre-study treatment & \\
Surgery & $163(54.7)$ \\
Radiotherapy & $16(5.4)$ \\
Surgery+radiotherapy & $48(16.1)$ \\
Clinical characteristics & $n($ range) \\
Male (\%) & $182(58.1)$ \\
Female (\%) & $131(41.9)$ \\
Age (years) & $49.7(17-77)$ \\
Current smoker (\%) & 25.2 \\
Adult onset GHD (\%) & 89.8 \\
Isolated GHD (\%) & 11.3 \\
Duration of GHD (years) & $4.48(0-47)$ \\
Sex steroids & $134 / 182(73.6)$ \\
Men (\%) & $50 / 131(38.2)$ \\
Women (\%) & $52(16.6)$ \\
Diabetes insipidus (\%) & \\
\hline
\end{tabular}

${ }^{a}$ Nonfunctioning pituitary adenoma.

${ }^{b}$ Empty sella, meningioma, apoplexy, Sheehan, trauma, sarcoidosis, cystic lesion, histiocytosis, congenital hypopituitarism, dysgerminoma, granular cells tumor, hamartoma, medulloblastoma, rhabdomyosarcoma, septooptic dysplasia, TSH adenoma, and Wegener granulomatosis. 
were retested and restarted on GH replacement in adulthood. Patients with previous treatment for Cushing's disease $(n=20)$ and acromegaly $(n=10)$ were in remission before entering the study and fulfilled international diagnostic criteria for GHD (26). The most common etiology of GHD was nonfunctioning pituitary adenoma (40.9\%). When required, patients received adequate and stable replacement therapy with glucocorticoids, thyroid hormone, sex steroids, and desmopressin for at least 6 months before commencing $\mathrm{GH}$.

Written informed consent was obtained from all patients. The study was approved by the Ethics Committee at the University of Gothenburg (Sweden) and performed in accordance with the Declaration of Helsinki.

\section{Study design}

Patients were prospectively enrolled (between years 1993 and 2009) in an open label treatment protocol, and serum samples were obtained at baseline, 1 week, 6 months, and 1 year after start of GH replacement therapy. The first 65 included patients who received a weight-based GH dose (mean dose $0.52 \mathrm{mg} /$ day, range 0.33-2.64), a dosing regimen which was abandoned after a few years and replaced by an individualized treatment strategy (27). All patients received recombinant human $\mathrm{GH}$, administered s.c. every evening, which was titrated against serum IGF1 collected after 1 and 4 weeks of GH replacement and every 3 months subsequently to maintain age-adjusted serum IGF1 levels.

\section{Anthropometry and body composition}

Body weight (BW) was measured in the morning to the nearest $0.1 \mathrm{~kg}$ and body height was measured barefoot to the nearest $0.1 \mathrm{~cm}$. BMI was calculated as BW (kg) divided by height squared $\left(\mathrm{m}^{2}\right)$. Waist circumference was measured in the standing position with a flexible plastic tape placed midway between the lower rib margin and the iliac crest; hip girth was measured at the widest part of the hip. Body fat (BF) was determined by dual energy X-ray absorptiometry (DEXA). The DEXA measurements were performed using a LUNAR-DPX-L DEXA scanner (LUNAR Radiation, Madison, WI, USA).

\section{Measurements and biochemistry}

Systolic blood pressure (SBP) and diastolic blood pressure (DBP) were measured after at least $5 \mathrm{~min}$ of supine rest using the sphygmomanometric cuff method. Blood chemistry analyses were performed at the Department of Clinical Chemistry, Sahlgrenska University Hospital (accredited according to ISO/IEX 17025). IGF1 levels were determined in serum samples collected in the morning after an overnight fast, using a hydrochloric acid-ethanol extraction RIA with authentic serum IGF1 for labeling (Nichols Institute of Diagnostics, San Juan Capistrano, CA, USA). After 2004, the serum IGF1 levels were determined using an automated chemiluminescent immunoassay (Advantage) from Nichols. From September 2006, serum IGF1 was determined using an automated chemiluminescent assay system (IMMULITE 2500, Diagnostic Products Corp., Los Angeles, CA, USA). Both assays had a detection limit $\leq 20 \mu \mathrm{g} / 1$ and an inter-assay coefficient of variation $\leq 9.3 \%$. The WHO NIBSC 1 st IRR $87 / 518$ standard was used for calibration throughout the study period.

\section{SNP selection and genetic analyses}

The selection of candidate genes was based on their wellestablished function in the GH signaling cascade according to previous publications. Further selection of candidate SNPs within these genes was also based on earlier reports on functionality and/or associations with aspects of GH function. Owing to the limited size of our cohort, we chose to only include SNPs with a minor allele frequency (MAF) $>10 \%$ in the HapMap CEU Panel. Genomic DNA was isolated from whole blood using the Flexigene DNA Kit (Qiagen). The following genes and SNPs were selected for analysis: GHR SNP rs6873545, JAK2 SNPs rs3780378 and rs7849191, PIK3CB SNP rs361072, SOCS2 SNP rs11107116 and finally STAT5B SNP rs6503691. The GHR d3/fl polymorphism was analyzed using tagSNP rs6873545, as previously validated (28), and genotyped using TaqMan SNP genotyping. The remaining SNPs were genotyped on the Sequenom Platform (Sequenom, Inc., San Diego, CA, USA).

In the TaqMan SNP genotyping, $10 \mathrm{ng}$ genomic DNA were added to a reaction mix containing $1 \times$ TaqMan Genotyping PCR Master Mix (Applied Biosystems) and SNP-specific genotyping assay (C_28966089_10; Applied Biosystems). Reactions were carried out in $5 \mu$ l reaction mix on 384-well plates (Applied Biosystems). PCR amplification was performed using a 384 dual GeneAMP PCR system 9700 instrument (Applied Biosystems) and allele detection was carried out in an ABI Prism 7900HT Sequence Detection System instrument (Applied Biosystems). The Sequenom genotyping was performed using matrix-assisted laser desorption/ionization time of flight mass spectrometry (Sequenom, Inc.), as described elsewhere (29). 


\section{Statistical analyses}

Statistical analysis was performed using IBM SPSS Statistics v20.0 (SPSS, Inc.). Paired-samples Student's $t$-tests were used to compare values between visits. Interactions between genotype groups and categorical variables such as sex were analyzed using $\chi^{2}$ test. ANOVA was used to test for interactions between genotypes and quantitative parameters such as age and $\mathrm{GH}$ dose. Linear regression analyses were performed, adjusted for appropriate confounders at baseline (age and sex), at 1 week (age, sex, and baseline GH dose), at 6 months (age, sex, and the 6 months GH dose), and at 1 year (age, sex, and the 1 year GH dose). The percentage change in serum IGF1 was calculated as either ((IGF1_timepoint-IGF1_baseline)/IGF1_baseline $) \times 100$ or ((IGF1_timepoint-IGF1_1 week)/IGF1_1 week) $\times 100$. A $P<0.05$ was considered statistically significant.

\section{Results}

\section{Genotyping}

Genotyping success rate was $>97.4 \%$ (mean 98.8\%) for all assays. MAFs varied between 12.5 and $48.2 \%$, and all SNPs except rs3780378 conformed to the Hardy-Weinberg equilibrium (HWE; SNP rs3780378 was subsequently excluded from further statistical analyses). For MAFs and HWE $\chi^{2}$ test $P$ values, see Table 2 .

\section{Genotypes and baseline clinical characteristics}

General baseline characteristics of the patients are presented in Table 1. Genotypes were not related to baseline clinical characteristics and/or parameters; including baseline serum IGF1 levels, CO-GHD, and/or previous acromegaly.

\section{Clinical response to $\mathrm{GH}$ replacement therapy}

Mean daily GH dose at commencement and at 1 week was $0.23 \mathrm{mg}$ (range $0.03-2.64 \mathrm{mg}$ ) and at 12 months of treatment it was $0.44 \mathrm{mg}$ (range 0.08-1.98 mg). Average serum IGF1 concentration ( \pm s.D.) at baseline was 108.3 $( \pm 71.4) \mu \mathrm{g} / \mathrm{l}$, which increased to $172.2( \pm 113.6) \mu \mathrm{g} / \mathrm{l}$ $(P<0.001)$ after 1 week of GH replacement, corresponding to a mean increase of $58.8( \pm 71.3) \mu \mathrm{g} / \mathrm{l}$ (range -189.0 to $423.0 \mu \mathrm{g} / \mathrm{l})$. After 6 and 12 months of GH replacement, average serum IGF1 concentrations ( \pm s.D.) had increased by $137.3( \pm 103.1) \mu \mathrm{g} / \mathrm{l}$ and $142.8( \pm 101.1) \mu \mathrm{g} / \mathrm{l}$ respectively. BW was unchanged, while BF percentage was reduced by $2.5( \pm 3.3) \%(P<0.001)$, waist-to-hip ratio reduced by $0.02( \pm 0.06)(P<0.001)$, and SBP and DBP were reduced by 1.7 and $1.5( \pm 15.0$ and \pm 9.4$) \mathrm{mmHg}(P=0.05$ and $P=0.007$ respectively) after 12 months of therapy.

\section{Genotypes and early (short-term) response to $\mathrm{GH}$ replacement therapy}

In linear regression analyses adjusting for sex, age, and baseline GH dose, SNPs rs6873545 (GHR) and rs361072 (PIK3CB) were significantly associated with the percentage of change in IGF1 concentrations at 1 week of $\mathrm{GH}$ replacement therapy ( $P=0.016$ and $P=0.025$ respectively). Homozygotes of the fl-GHR had on average a $45 \%$ larger increase in serum IGF1 levels than individuals carrying the d3-GHR. Conversely, minor allele carriers of SNP rs361072 showed a $37.5 \%$ larger increase in serum IGF1 levels than homozygotes of the major allele. For illustration, see Fig. 1 (figure shows unadjusted means). The magnitude of the genotype effect did not materially change when analyses where repeated without those patients who were treated using the old $\mathrm{GH}$ dose regimen. Genotypes were not associated with crude serum IGF1 concentrations at 1 week of GH replacement. Effect sizes and $P$ values are summarized in Table 3 .

Table 2 dbSNP ID, abbreviated, associated gene names, MAFs, genotype counts (MM, Mm, and mm), and HWE $\chi^{2}$ test $P$ values for 313 adults with GHD.

\begin{tabular}{lll}
\hline dbSNP ID & & Gene \\
\cline { 1 - 1 } rs6873545 & & GHR \\
rs361072 & PIK3CB \\
rs7849191 & JAK2 \\
rs3780378 & JAK2 \\
rs6503691 & STAT5B \\
rs11107116 & SOCS2 \\
\hline
\end{tabular}

\begin{tabular}{c}
\hline MAF \\
\hline $23.8 \%(\mathrm{C})$ \\
$40.2 \%(\mathrm{G})$ \\
$36.9 \%(\mathrm{~T})$ \\
$48.2 \%(\mathrm{C})$ \\
$12.5 \%(\mathrm{~T})$ \\
$26.6 \%(\mathrm{~T})$ \\
\hline
\end{tabular}

$\begin{array}{r}\hline \text { MM } \\ \hline 182 \\ 108 \\ 123 \\ 73 \\ 242 \\ 168 \\ \hline\end{array}$

$\begin{array}{r}\hline \mathbf{M m} \\ \hline 107 \\ 157 \\ 140 \\ 170 \\ 64 \\ 119 \\ \hline\end{array}$

\begin{tabular}{c}
$\mathbf{m m}$ \\
\hline 20 \\
47 \\
43 \\
62 \\
7 \\
23
\end{tabular}

\begin{tabular}{c}
\hline HWE $\chi^{2} \boldsymbol{P}$ \\
\hline 0.430 \\
0.412 \\
0.755 \\
0.042 \\
0.267 \\
0.761 \\
\hline
\end{tabular}

MAF, minor allele frequencies; MM, homozygotes of the major allele; Mm, heterozygotes; mm, homozygotes of the minor allele; HWE, Hardy-Weinberg equilibrium. Statistically significant $P$ value is shown in italics. 


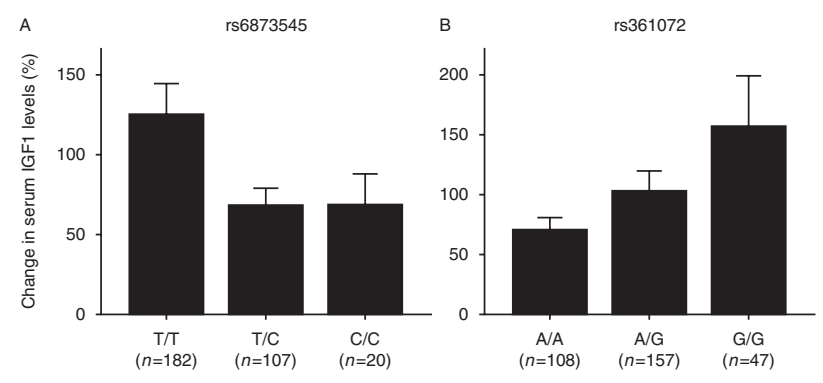

\section{Figure 1}

Percentage change in serum IGF1 levels at 1 week of GH replacement therapy in 313 adult patients with GHD, for genotype groups of SNPs rs6873545 (GHR) and rs361072 (PIK3CB). Bars show the unadjusted average percentage change in serum IGF1 concentrations at 1 week of GH replacement therapy (early response) \pm s.E.M. Numbers within brackets correspond to the number of subjects carrying the respective genotype. (A) Difference in percentage change in serum IGF1 levels for genotype groups (T/T, T/C, and C/C) of GHR SNP rs6873545. (B) Shows the same, but for genotype groups (A/A, A/G, and G/G) of PIK3CB SNP rs361072.

\section{Genotypes and long-term response to $\mathrm{GH}$ replacement therapy}

As compared with baseline, SNP rs6873545 (GHR) was associated with the percentage change in IGF1 levels at 6 months $(P=0.041)$ and at 1 year $(P=0.041)$. SNP rs361072 (PIK3CB) was significantly associated with the percentage change in IGF1 levels at 6 months $(P=0.047)$ of $\mathrm{GH}$ therapy. When comparing the serum IGF1 response between 1 week and 6 and 12 months, no SNP was significantly associated with the long-term (6 months or 1 year) responses to GH replacement therapy (Table 3).

\section{Discussion}

In this present study on adults receiving GH replacement therapy for 1 year, we found that among the studied SNPs within the GH signaling pathway, GHR SNP rs6873545 and PIK3CB SNP rs361072 could significantly predict the early (short-term) IGF1 response to GH replacement therapy. In contrast to previous studies on the association between the GHR $\mathrm{d} 3 / \mathrm{fl}$ polymorphism and long-term response to $\mathrm{GH}$ treatment, we found that the fl-GHR was strongly associated with a larger short-term serum IGF1 response.

The golden standard for GH replacement treatment regime is to use an individualized GH dose titration (27). A patient sensitive to $\mathrm{GH}$ will require a low $\mathrm{GH}$ dose to normalize serum IGF1 concentrations and a patient less sensitive to $\mathrm{GH}$ will require a higher $\mathrm{GH}$ dose. This treatment regime allows for an individualized approach, which on the other hand is likely to mask clinical and genetic predictors of response, as the response variable is being adjusted consecutively during the treatment period. In order to increase the possibilities to detect the effect of genetics on $\mathrm{GH}$ responsiveness, we investigated the early response to $\mathrm{GH}$ (at 1 week), when neither $\mathrm{GH}$ dose titration nor other possible external confounders are expected to have impacted on the treatment response. Using this approach, we were able to demonstrate that GHR SNP rs6873545 and PIK3CB SNP rs361072 were significantly associated with the IGF1 response to GH treatment.

SNP rs6873545 is a tagSNP for the GHR d3/fl polymorphism, which has been extensively studied in both pediatric and adult GH treatment studies (7). In a study on adult GHD patients, it was demonstrated that d3-GHR carriers had a larger increase in serum IGF1 levels, more marked decrease in total- and LDL-cholesterol levels, and a greater increase in serum HDL-cholesterol levels after 1 year of GH replacement therapy (11). Another study showed that d3-GHR carriers require 25\% less GH during replacement therapy than fl-GHR carriers (10). Other studies have, however, not shown associations between $\mathrm{d} 3 / \mathrm{fl}$ genotype and response to $\mathrm{GH}$ in adults $(8,9)$.

Table 3 Summary of SNP info, effect size in percentage of change in serum IGF1 concentrations and $P$ values from regression analyses in 313 adult patients with GHD during 1 year of GH replacement therapy. Results from linear regression analyses adjusted for the confounders: sex, age, and GH dose. The long-term (6 months and 1 year) percentage of change in serum IGF1 levels was calculated using the 1 week serum IGF1 levels as reference value, to denote that the long-term response corresponds to the change in serum IGF1 levels taking place after the rapid response has occurred. Effect sizes refer to the adjusted difference between the heterozygote group and homozygotes of the major allele for each SNP (in percentage), negative values corresponds to a lower percentage of increase in serum IGF1 levels during GH replacement therapy for the heterozygotes vs the homozygotes of the major allele.

\begin{tabular}{|c|c|c|c|c|}
\hline \multicolumn{2}{|l|}{ SNP info } & \multicolumn{3}{|c|}{ Percentage change in serum IGF1 } \\
\hline dbSNP ID & Gene & $\begin{array}{l}1 \text { week } \\
(n=253)\end{array}$ & $\begin{array}{l}6 \text { months } \\
(n=251)\end{array}$ & $\begin{array}{c}1 \text { year } \\
(n=256)\end{array}$ \\
\hline rs6873545 & GHR & $-45.3(0.016)$ & $-19.7(0.457)$ & $-24.5(0.382)$ \\
\hline rs361072 & $P I K 3 C B$ & $37.5(0.025)$ & $-3.3(0.894)$ & $-9.6(0.700)$ \\
\hline rs7849191 & $J A K 2$ & $8.8(0.610)$ & $1.7(0.945)$ & $-0.8(0.947)$ \\
\hline rs6503691 & STAT5B & $-9.1(0.717)$ & $-3.9(0.910)$ & $-4.0(0.913)$ \\
\hline rs11107116 & SOCS2 & $29.9(0.119)$ & $-19.2(0.477)$ & $-16.4(0.564)$ \\
\hline
\end{tabular}

$P$ values are shown within brackets and significant $P$ values are shown in italics. 
In our study, 1 week of GH replacement increased the serum IGF1 concentrations on average by 100\% (unadjusted values). Interestingly, when dividing the cohort into genotype groups for rs6873545, the fl-GHR homozygotes were responding better to $\mathrm{GH}$ replacement than heterozygotes and d3-GHR homozygotes in terms of the early response in IGF1 (1 week). Unadjusted, on average, fl/fl subjects had increased their serum IGF1 levels by $126 \%$ after 1 week of GH treatment, whereas both d3/fl and d3/d3 subjects had increased theirs by $69 \%$. This is in contrast to previously published data. There may be several reasons for this discrepancy since there are some obvious differences between our study protocol and previous ones. First, to our knowledge, this is by far the largest adult GHD cohort in which the GHR d3/fl polymorphism has been analyzed. Also, no reports on an early (1 week) IGF1 response, before any dose titration has occurred, are to be found in the literature. We argue that the early response to a fixed dose of $\mathrm{GH}$ is a clean study model and the very short period of observation is likely not influenced by other external confounders that may occur during a more long-term treatment. Further, we analyzed the percentage of change in serum IGF1, as opposed to other publications analyzing the crude serum IGF1 levels or delta. The reason for our choice is that we believe that the percentage of change in IGF1 levels is a better variable for response prediction because of the large baseline differences in serum IGF1 concentrations in adults with GHD (30).

Some of the metabolic effects of $\mathrm{GH}$ are the results of activation of PI3Ks, such as PIK3CB. Interestingly, the G-allele of PIK3CB SNP rs361072 has been shown to create a GATA-binding site capable of increasing transcription of PIK3CB (19). In addition, this SNP has been shown to be associated with serum IGF1 levels and longevity (20). In our study, rs361072 was associated with the early IGF1 response (1 week) to $\mathrm{GH}$ replacement. On average, after 1 week of GH replacement, the G/G subjects had increased their serum IGF1 concentrations by $157.6 \%$, in comparison to A/G (103.4\%) and A/A (71.0\%) subjects (unadjusted). In accordance with previous findings, which have shown that homozygotes of the G-allele of this SNP had higher free serum IGF1 levels (20), in our study the G-allele was associated with a larger IGF1 response to GH.

The major strength of this study is that we analyzed the early and long-term response to $\mathrm{GH}$ replacement therapy separately. Our study also has some limitations that should be mentioned. First, the candidate gene approach that we used is dependent on publicly available data and previous findings, and it is therefore possible that some important SNPs may not have been included in the analysis. Another limitation is the sample size $(n=313)$. Although this is the largest study of its kind, larger sample sizes are needed in order to achieve more reliable results that can be successfully replicated in other studies.

To conclude, this study is the first to demonstrate an impact of SNPs within the GH signaling cascade on the early IGF1 response to GH replacement therapy in GHD adults. The large effect sizes of the genotypes strongly indicate that they are likely to have a clinically meaningful influence on the response to $\mathrm{GH}$; however, future studies are needed to demonstrate whether using genotype can improve the management of adult patients with GHD during replacement therapy.

\section{Declaration of interest}

G Johannsson is a member of the international KIMS advisory board and has received lecture fees from Eli Lilly, Merck Serono, NovoNordisk, and Pfizer. The other authors have no conflicts of interest.

\section{Funding}

This project has received financial support from the Swedish federal government under the LUA/ALF agreement, NovoNordisk, and Pfizer.

\section{Acknowledgements}

We are indebted to all those who aided in performing this study, especially the late Sigrid Lindstrand. We also thank Ingrid Hansson, Jenny Tiberg, Lena Wirén, Anna-Lena Jönsson, Annika Reibring, Anna Olsson, and Annika Alklind at the Centre for Endocrinology and Metabolism, Sahlgrenska University Hospital, for their skilful technical support, the patients who participated in the study and the Mutation Analysis Facility at Karolinska University Hospital for their work on the Sequenom part of this project, especially Linda Berglind and Kristina Duvefelt.

\section{References}

1 Johannsson G \& Bengtsson BA. Growth hormone and the metabolic syndrome. Journal of Endocrinological Investigation 199922 41-46.

2 Rosen T \& Bengtsson BA. Premature mortality due to cardiovascular disease in hypopituitarism. Lancet 1990336 285-288. (doi:10.1016/ 0140-6736(90)91812-O)

3 Boguszewski CL, Meister LH, Zaninelli DC \& Radominski RB. One year of GH replacement therapy with a fixed low-dose regimen improves body composition, bone mineral density and lipid profile of GH-deficient adults. European Journal of Endocrinology 2005152 67-75. (doi:10.1530/eje.1.01817)

4 Cook DM, Ludlam WH \& Cook MB. Route of estrogen administration helps to determine growth hormone $(\mathrm{GH})$ replacement dose in GH-deficient adults. Journal of Clinical Endocrinology and Metabolism 199984 3956-3960. (doi:10.1210/jc.84.11.3956)

5 Johannsson G, Bjarnason R, Bramnert M, Carlsson LM, Degerblad M, Manhem P, Rosen T, Thoren M \& Bengtsson BA. The individual responsiveness to growth hormone $(\mathrm{GH})$ treatment in $\mathrm{GH}$-deficient adults is dependent on the level of GH-binding protein, body mass index, age, and gender. Journal of Clinical Endocrinology and Metabolism 199681 1575-1581. (doi:10.1210/jc.81.4.1575) 
6 Barbosa EJ, Koranyi J, Filipsson H, Bengtsson BA, Boguszewski CL \& Johannsson G. Models to predict changes in serum IGF1 and body composition in response to GH replacement therapy in GH-deficient adults. European Journal of Endocrinology 2010162 869-878. (doi:10. 1530/EJE-09-0973)

7 Wassenaar MJ, Dekkers OM, Pereira AM, Wit JM, Smit JW, Biermasz NR \& Romijn JA. Impact of the exon 3-deleted growth hormone (GH) receptor polymorphism on baseline height and the growth response to recombinant human GH therapy in GH-deficient (GHD) and non-GHD children with short stature: a systematic review and meta-analysis. Journal of Clinical Endocrinology and Metabolism 200994 3721-3730. (doi:10.1210/jc.2009-0425)

8 Adetunji OR, MacFarlane IA, Javadpour M, Alfirevic A, Pirmohamed M $\&$ Blair JC. The d3/fl-GH receptor gene polymorphism does not influence quality of life and body composition in GH-deficient adults receiving GH replacement therapy. European Journal of Endocrinology 2009161 541-546. (doi:10.1530/EJE-09-0405)

9 Barbosa EJ, Palming J, Glad CA, Filipsson H, Koranyi J, Bengtsson BA, Carlsson LM, Boguszewski CL \& Johannsson G. Influence of the exon 3-deleted/full-length growth hormone (GH) receptor polymorphism on the response to GH replacement therapy in adults with severe GH deficiency. Journal of Clinical Endocrinology and Metabolism 200994 639-644. (doi:10.1210/jc.2008-0323)

10 Meyer S, Schaefer S, Stolk L, Arp P, Uitterlinden AG, Plockinger U, Stalla GK, Tuschy U, Weber MM, Weise A et al. Association of the exon 3 deleted/full-length GHR polymorphism with recombinant growth hormone dose in growth hormone-deficient adults. Pharmacogenomics 200910 1599-1608. (doi:10.2217/pgs.09.91)

11 van der Klaauw AA, van der Straaten T, Baak-Pablo R, Biermasz NR, Guchelaar HJ, Pereira AM, Smit JW \& Romijn JA. Influence of the d3-growth hormone (GH) receptor isoform on short-term and longterm treatment response to GH replacement in GH-deficient adults. Journal of Clinical Endocrinology and Metabolism 200893 2828-2834. (doi:10.1210/jc.2007-2728)

12 Barton DE, Foellmer BE, Wood WI \& Francke U. Chromosome mapping of the growth hormone receptor gene in man and mouse. Cytogenetics and Cell Genetics 198950 137-141. (doi:10.1159/000132743)

13 Godowski PJ, Leung DW, Meacham LR, Galgani JP, Hellmiss R, Keret R, Rotwein PS, Parks JS, Laron Z \& Wood WI. Characterization of the human growth hormone receptor gene and demonstration of a partial gene deletion in two patients with Laron-type dwarfism. PNAS 198986 8083-8087. (doi:10.1073/pnas.86.20.8083)

14 Leung KC. Regulation of cytokine receptor signaling by nuclear hormone receptors: a new paradigm for receptor interaction. DNA and Cell Biology 200423 463-474. (doi:10.1089/1044549041562285)

15 Zhu T, Goh EL, Graichen R, Ling L \& Lobie PE. Signal transduction via the growth hormone receptor. Cellular Signalling 200113 599-616. (doi:10.1016/S0898-6568(01)00186-3)

16 Flores-Morales A, Greenhalgh CJ, Norstedt G \& Rico-Bautista E. Negative regulation of growth hormone receptor signaling. Molecular Endocrinology 200620 241-253. (doi:10.1210/me.2005-0170)

17 Leung KC, Doyle N, Ballesteros M, Sjogren K, Watts CK, Low TH, Leong GM, Ross RJ \& Ho KK. Estrogen inhibits GH signaling by suppressing GH-induced JAK2 phosphorylation, an effect mediated by SOCS-2. PNAS 2003100 1016-1021. (doi:10.1073/pnas.0337600100)

18 Lanning NJ \& Carter-Su C. Recent advances in growth hormone signaling. Reviews in Endocrine \& Metabolic Disorders 20067 225-235. (doi:10.1007/s11154-007-9025-5)

19 Le Stunff C, Dechartres A, Mariot V, Lotton C, Trainor C, Miraglia Del Giudice E, Meyre D, Bieche I, Laurendeau I, Froguel P et al. Association analysis indicates that a variant GATA-binding site in the PIK3CB promoter is a Cis-acting expression quantitative trait locus for this gene and attenuates insulin resistance in obese children. Diabetes 200857 494-502. (doi:10.2337/db07-1273)

20 Bonafe M, Barbieri M, Marchegiani F, Olivieri F, Ragno E, Giampieri C, Mugianesi E, Centurelli M, Franceschi C \& Paolisso G. Polymorphic variants of insulin-like growth factor I (IGF-I) receptor and phosphoinositide 3-kinase genes affect IGF-I plasma levels and human longevity: cues for an evolutionarily conserved mechanism of life span control. Journal of Clinical Endocrinology and Metabolism 200388 3299-3304. (doi:10.1210/jc.2002-021810)

21 Ge D, Gooljar SB, Kyriakou T, Collins LJ, Swaminathan R, Snieder H, Spector TD \& O'Dell SD. Association of common JAK2 variants with body fat, insulin sensitivity and lipid profile. Obesity 200816 492-496. (doi:10.1038/oby.2007.79)

22 Vaclavicek A, Bermejo JL, Schmutzler RK, Sutter C, Wappenschmidt B, Meindl A, Kiechle M, Arnold N, Weber BH, Niederacher D et al. Polymorphisms in the Janus kinase 2 (JAK)/signal transducer and activator of transcription (STAT) genes: putative association of the STAT gene region with familial breast cancer. Endocrine-Related Cancer 200714 267-277. (doi:10.1677/ERC-06-0077)

23 Makimura M, Ihara K, Kojima-Ishii K, Nozaki T, Ohkubo K, Kohno H, Kishimoto J \& Hara T. The signal transducer and activator of transcription $5 \mathrm{~B}$ gene polymorphism contributes to the cholesterol metabolism in Japanese children with growth hormone deficiency. Clinical Endocrinology 201174 611-617. (doi:10.1111/j.1365-2265.2011.03980.x)

24 Sovio U, Bennett AJ, Millwood IY, Molitor J, O'Reilly PF, Timpson NJ, Kaakinen M, Laitinen J, Haukka J, Pillas D et al. Genetic determinants of height growth assessed longitudinally from infancy to adulthood in the northern Finland birth cohort 1966. PLoS Genetics 20095 e1000409. (doi:10.1371/journal.pgen.1000409)

25 Weedon MN, Lango H, Lindgren CM, Wallace C, Evans DM, Mangino M, Freathy RM, Perry JR, Stevens S, Hall AS et al. Genome-wide association analysis identifies 20 loci that influence adult height. Nature Genetics 200840 575-583. (doi:10.1038/ng.121)

26 Ho KK. Consensus guidelines for the diagnosis and treatment of adults with GH deficiency II: a statement of the GH Research Society in association with the European Society for Pediatric Endocrinology, Lawson Wilkins Society, European Society of Endocrinology, Japan Endocrine Society, and Endocrine Society of Australia. European Journal of Endocrinology 2007157 695-700. (doi:10.1530/EJE-07-0631)

27 Johannsson G, Rosen T \& Bengtsson BA. Individualized dose titration of growth hormone (GH) during GH replacement in hypopituitary adults. Clinical Endocrinology 199747 571-581. (doi:10.1046/j.13652265.1997.3271123.x)

28 Glad CA, Johannsson G, Carlsson LM \& Svensson PA. Rapid and high throughput genotyping of the growth hormone receptor exon 3 deleted/full-length polymorphism using a tagSNP. Growth Hormone \& IGF Research 201020 270-273. (doi:10.1016/j.ghir.2010.02.004)

29 Barbosa EJ, Glad CA, Nilsson AG, Filipsson Nyström H, Gotherstrom G, Svensson PA, Vinotti I, Bengtsson BA, Nilsson S, Boguszewski CL et al. Genotypes associated with lipid metabolism contribute to differences in serum lipid profile of GH-deficient adults before and after GH replacement therapy. European Journal of Endocrinology 2012167 353-362. (doi:10.1530/EJE-12-0263)

30 Svensson J, Johannsson G \& Bengtsson BA. Insulin-like growth factor-I in growth hormone-deficient adults: relationship to population-based normal values, body composition and insulin tolerance test. Clinical Endocrinology 199746 579-586. (doi:10.1046/j.1365-2265. 1997.1851001.x)

Received 21 August 2013

Revised version received 4 October 2013

Accepted 9 October 2013 